\title{
PENGOLAHAN DAN PERNGARSIPAN DATA PADA FAKULTAS UNLAM BANJARMASIN-BANJARBARU
}

\author{
${ }^{1}$ Iqbal Firdaus \\ ${ }^{2}$ Silvia Ratna \\ Fakultas Teknologi Informasi, Universitas Islam Kalimantan \\ Muhammad Arsyad Al Banjari Banjarmasin \\ Email : iqbal.firdaus@gmail.com \\ Fakultas Teknologi Informasi, Universitas Islam Kalimantan \\ Muhammad Arsyad Al Banjari Banjarmasin \\ Email : via.Borneo@gmail.com
}

\begin{abstract}
ABSTRAK
Aplikasi pengolahan dan pengarsipan data ini dibuat untuk menunjang agar pembuatan, pengarsipan, pencetakan, penyimpanan data dan laporan dapat dilakukan dengan mudah dan waktu yang singkat serta akurat dan lengkap. Aplikasi pengolahan dan pengarsipan data ini dibangun dengan menggunakan bahasa pemograman Java NetBeans dan database MySQL.

Penelitian ini menggunakan jenis penelitian terapan. Data yang dikumpulkan menggunakan teknik observasi dan wawancara dengan menggunakan teori pengembangan software SDLC (Software Development Life Cycle).

Aliran data dan perancangan aplikasi pengolahan dan pengarsipan data ini menggunakan Diagram Konteks dan Data Flow Diagram (DFD). Aplikasi pengolahan dan pengarsipan data ini dapat membantu dalam mempermudah pembuatan dan pengarsipan data diri, SK dan surat keterangan gaji di Fakultas Teknik Unlam Banjarmasin-Banjarbaru.
\end{abstract}

Kata Kunci: Aplikasi, Fakultas Teknik Unlam Banjarmasin-Banjarbaru, Java NetBeans, MySQL

\section{PENDAHULUAN}

Fakultas Teknik Unlam (Universitas Lambung Mangkurat) didirikan pada tahun 1965, merupakan Fakultas ke-7 yang didirikan di Unlam. Pada saat Fakultas Teknik didirikan, Unlam sudah menjadi Universitas Negeri yang memiliki 2 lokasi, yaitu Banjarmasin dan Banjarbaru. Fakultas Teknik dibentuk pertama kali di Banjarbaru. Saat ini (tahun 2017), Fakultas Teknik Unlam sudah memiliki 7 Program Studi S1 dan 1 Program Pasca Sarjana (S2), yaitu: Program Studi Teknik Sipil, Program Studi Teknik Arsitektur, Program Studi Teknik Pertambangan, Program Studi Teknik Kimia, Program Studi Teknik Lingkungan, Program Studi Teknik Mesin, Program Studi Teknik Informatika, dan Program Studi Magister Teknik Sipil. Fakultas
Teknik Unlam memiliki Tenaga Pendidik berjumlah 117 orang dan Tenaga Kependidikan berjumlah 28 orang.

Selain Tenaga Pendidik dan Tenaga Kependidikan Fakultas Teknik Unlam memiliki PPNPN (Pegawai Pemerintah Non Pegawai Negeri) yaitu Dosen Kontrak berjumlah 14 orang dan Pramubakti Kontrak berjumlah 31 orang yang mendukung untuk berbagai kegiatan Operasional.

Pada Fakultas Teknik Unlam BanjarmasinBanjarbaru, proses pengolahan dan pengarsipan data PPNPN pada sistem yang sedang berjalan masih bersifat belum otomatis dalam arti pengarsipan datanya masih berbentuk arsip-arsip. Misalkan saja salah satunya pada proses pencarian SK dosen dan pramubakti, dibutuhkan waktu yang lama karena belum menggunakan software aplikasi 
khusus yang dapat membantu dalam proses pengolahan dan pengarsipan data PPNPN.

\section{LANDASAN TEORI}

\section{Pengertian Sistem}

Menurut (Tata Sutabri, 2012), terdapat dua kelompok pendekatan di dalam pendefinisian sistem, yaitu kelompok yang menekankan pada prosedur dan kelompok yang menekankan pada elemen atau komponennya. Pendekatan yang menekankan pada prosedur mendefinisikan sistem sebagai suatu jaringan kerja prosedurprosedur yang saling berhubungan, berkumpul bersama-sama untuk melakukan suatu kegiatan atau untuk menyelesaikan suatu sasaran tertentu. Sedangkan pendekatan sistem yang lebih menekankan pada elemen atau komponen mendefinisikan sistem sebagai kumpulan elemen yang berinteraksi untuk mencapai suatu tujuan tertentu. Kedua kelompok definisi ini adalah benar dan tidak bertentangan. Yang berbeda adalah cara pendekatannya.

Secara sederhana sistem dapat diartikan sebagai suatu kumpulan atau himpunan dari unsur, komponen, atau variabel yang terorganisasi, saling berinteraksi, saling tergantung satu sama lain dan terpadu. tampak secara fisik, tetapi juga hal-hal yang mungkin bersifat abstrak atau konseptual, seperti misi, pekerjaan, kegiatan, kelompok informal, dan lain sebagainya.

Unsur-unsur yang mewakili suatu sistem secara umum adalah masukan (input), pengolahan (processing) dan keluaran (output). Di samping itu suatu sistem senantiasa tidak terlepas dari lingkungan sekitarnya. Maka umpan balik (feedback) selain berasal dari output, juga dapat berasal dari lingkungan sistem tersebut. Organisasi dipandang sebagai suatau sistem yang juga memiliki semua unsur ini.

Istilah sistem banyak dipakai sekarang ini. Banyak orang berbicara mengenai sistem perbankan, sistem akutansi, sistem inventori, sistem persediaan, sistem pemasaran, sistem pendidikan, sistem perangkat lunak, sistem tata surya, sistem teologi, dan masih banyak lagi bentuk sistem yang lainnya. Sebuah sistem terdiri atas bagian-bagian atau komponen yang terpadu untuk suatu tujuan. Model dasar dari bentuk sistem ini adalah adanya masukan, pengolahan, dan keluaran. Meskipun demikian, sistem ini dapat dikembangkan hingga menyertakan media penyimpanan. Sebuah sistem dapat berupa sistem terbuka dan tertutup. Sebagai informasi biasanya sistem terbuka, yang berarti bahwa sistem tersebut dapat menerima berbagai masukan dari lingkungan sekitarnya.

\section{Pengertian Informasi}

Menurut (Tata Sutabri, 2012), Informasi adalah data yang telah diklasifikasikan atau diolah atau diinterprestasikan untuk digunakan dalam proses pengambilan keputusan. Sistem pengolahan informasi akan mengolah data menjadi informasi atau mengolah data dari bentuk tak berguna menjadi berguna bagi yang menerimanya. Nilai informasi berhubungan dengan keputusan. Bila tidak ada pilihan atau keputusan maka informasi tidak diperlukan.

Sumber dari informasi adalah data. Data meruakan kenyataan yang menggambarkan suatu kejadian serta merupakan suatu kesatuan yang nyata, dan merupakan bentuk yang masih mentah sehingga perlu diolah lebih lanjut melalui suatu model untuk menghasilkan informasi

\section{Pengertian Sistem Informasi}

Menurut (Tata Sutabri, 2012), Sistem informasi adalah suatu sistem di dalam suatu organisasi yang mempertemukan kebutuhan pengolahan transaksi harian yang mendukung fungsi operasi organisasi yang bersifat manajerial dengan kegiatan strategi dari suatu organisasi untuk dapat menyediakan laporanlaporan yang diperlukan oleh pihak luar tertentu.

\section{PPNPN (Pegawai Pemerintah Non Pegawai Negeri)}

Menurut (Portal KPPN, 2016), PPNPN (Pegawai Pemerintah Non Pegawai Negeri) adalah pegawai tidak tetap, pegawai honorer, staf khusus dan pegawai lain yang dibayarkan oleh Anggaran Pendapatan dan Belanja Negara.

Meliputi:

1. PPPK (Pegawai Pemerintah dengan Perjanjian Kerja) Pegawai yang diangkat berdasarkan perjanjian kerja untuk jangka waktu tertentu dalam rangka melaksanakan tugas pemerintahan; 
2. Staf khusus/staf ahli non pegawai negeri pada Kementerian Negara/Lembaga;

3. Komisioner/pegawai non pegawai negeri pada lembaga non struktural;

4. Dokter/Bidan PTT;

5. Dosen/Guru Tidak Tetap;

6. Satpam, Pengemudi, Petugas Kebersihan dan Pramubakti pada Satker yang membuat perjanjian kerja/kontrak dengan KPA/PPK untuk melaksanakan kegiatan operasional kantor; dan

7. Pegawai non pegawai negeri lainnya yang penghasilannya bersumber dari APBN.

\section{Arsip dan Kearsipan}

Menurut (Arjun, 2010), Arsip adalah rekaman kegiatan atau peristiwa dalam berbagai bentuk dan media sesuai dengan perkembangan teknologi informasi dan komunikasi yang dibuat dan diterima oleh lembaga negara, pemerintahan daerah, lembaga pendidikan, perusahaan, organisasi politik, organisasi kemasyarakatan, dan perseorangan dalam pelaksanaan kehidupan bermasyarakat, berbangsa, dan bernegara (UU No. 43 Tahun 2009).

\section{Java}

Menurut (Shalahuddin \& Rosa, 2010), Java adalah nama untuk sekumpulan teknologi untuk membuat dan menjalankan perangkat lunak pada komputer standalone ataupun pada lingkungan jaringan. Bahasa ini awalnya dibuat oleh James Gosling saat masih bergabung di Sun Microsystems saat ini merupakan bagian dari Oracle dan dirilis tahun 1995. Bahasa ini banyak mengadopsi sintaksis yang terdapat pada $\mathrm{C}$ dan $\mathrm{C}++$ namun dengan sintaksis model objek yang lebih sederhana serta dukungan rutin-rutin atas bawah yang minimal. Aplikasi-aplikasi berbasis java umumnya dikompilasi ke dalam p-code (bytecode) dan dapat dijalankan pada berbagai Mesin Virtual Java (JVM). Java merupakan bahasa pemrograman yang bersifat umum/nonspesifik (general purpose), dan secara khusus didesain untuk memanfaatkan dependensi implementasi seminimal mungkin. Karena fungsionalitasnya yang memungkinkan aplikasi java mampu berjalan di beberapa platform sistem operasi yang berbeda, java dikenal pula dengan slogannya, "Tulis sekali, jalankan di mana pun". Saat ini java merupakan bahasa pemrograman yang paling populer digunakan, dan secara luas dimanfaatkan dalam pengembangan berbagai jenis perangkat lunak aplikasi ataupun aplikasi berbasis web.

\section{Netbeans IDE}

Menurut (Prabawati, 2010), Netbeans merupakan salah satu IDE yang digunakan untuk melakukan pemograman baik menulis kode, mengkompilasi, mencari kesalahan, dan mendistribusikan program. Netbeans juga menyediakan paket yang lengkap dalam pemograman dari pemograman standar (aplikasi desktop), pemograman enterprise, dan pemograman perangkat mobile.

\section{XAMPP}

Menurut (Bunafit Nugroho, 2008), XAMPP adalah suatu bundel web server yang populer digunakan untuk coba-coba di Windows karena kemudahan instalasinya. Bundel program open source tersebut berisi antara lain server web Apache, interpreter PHP, dan basis data MySQL. Setelah menginstall XAMPP, kita bisa memulai pemrograman PHP di komputer sendiri maupun mencoba menginstall aplikasi-aplikasi web.

\section{MySQL}

Menurut (Kurniawan, Eri, \& Nur, 2011), SQL (Structured Query Language) adalah sebuah bahasa yang dipergunakan untuk mengakses data dalam basis data relasional. SQL juga dapat diartikan sebagai antar muka standar untuk sistem manajemen basis data relasional, termasuk sistem yang beroperasi pada komputer pribadi. SQL memungkinkan seorang pengguna untuk mengakses informasi tanpa mengetahui dimana lokasinya atau bagaimana informasi tersebut disusun.

MySQL adalah sebuah perangkat lunak sistem manajemen basis data SQL (bahasa Inggris: database management system) atau DBMS yang multi thread, dan multi-user. 
MySQL dimiliki dan disponsori oleh sebuah perusahaan komersial Swedia MySQL AB, dimana memegang hak cipta hampir atas semua kode sumbernya. Kedua orang Swedia dan satu orang Finlandia yang mendirikan MySQL AB adalah: David Axmark, Allan Larsson, dan Michael "Monty" Widenius.

MySQL adalah Relational Database Management System (RDBMS) yang didistribusikan secara gratis di bawah lisensi GPL (General Public License), dimana setiap orang bebas untuk menggunakan MySQL, namun tidak boleh dijadikan produk turunan yang bersifat komersial. MySQL sebenarnya merupakan turunan salah satu konsep utama dalam database sejak lama, yaitu SQL (Structured Query Language). SQL adalah sebuah konsep pengoperasian database, terutama untuk pemilihan atau seleksi dan pemasukan data, yang memungkinkan pengoperasian data dikerjakan dengan mudah secara otomatis.

\section{iReport}

Menurut (Kurniawan, Eri, \& Nur, 2011), iReport adalah report designer visual yang dibangun pada JasperReport. iReport bersifat intuitif dan mudah digunakan pembangun laporan visual atau desainer untuk JasperReport dan tertulis dalam kitab Java. Sebagai alternatif, terdapat tools iReport (dengan library JasperReport) yang dapat membantu dalam pembuatan laporan. Library JasperReport sendiri merupakan Java Library (JAR) yang bersifat open dan dirancang untuk menambahkan kemampuan pelaporan (reporting capabilities) pada aplikasi java. JasperReport memiliki sejumlah fitur, diantaranya adalah sebagai berikut:

1. Layout dan desain laporan yang fleksibel.

2. Dapat menampilkan laporan dalam bentuk teks maupun gambar (chart).

3. Dapat menghasilkan report dalam berbagai format, seperti: html, pdf, rtf, xls, dan csv.

4. Dapat menerima data dari berbagai sumber data, seperti: JDBC, Bean Collection, ResultSet, CSV, XML dan Hibernate.

\section{METODE PENELITIAN}

\section{Analisis Sistem Yang Berjalan}

Analisis sistem yang berjalan, proses pengolahan dan pengarsipan data PPNPN pada sistem yang sedang berjalan masih bersifat belum otomatis dalam arti pengarsipan datanya masih berbentuk arsip-arsip. Misalkan saja salah satunya pada proses pencarian SK dosen dan pramubakti, dibutuhkan waktu yang lama karena belum menggunakan software aplikasi khusus yang dapat membantu dalam proses pengolahan dan pengarsipan data PPNPN.

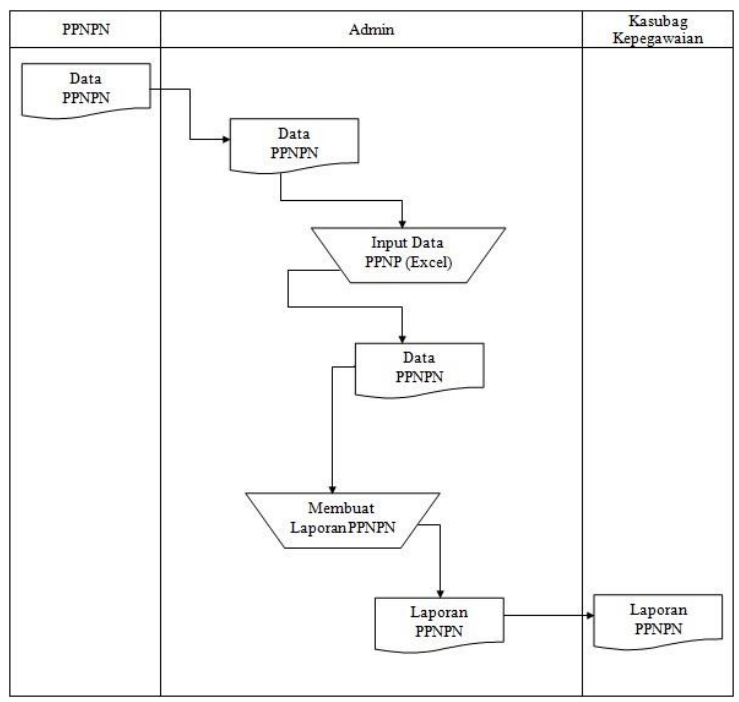

Keterangan :

Dosen dan pramubakti menyerahkan data kepada admin. Oleh admin diinput ke dalam excel. Dari admin akan dibuatkan laporan sebanyak 2 rangkap 1 diarsipkan dan 1 lagi diserahkan kepada kasubag kepegawaian. 


\section{Analisis Kebutuhan Sistem}

Analisis kebutuhan sistem sangat dibutuhkan guna menunjang penerapan sistem baru yang akan dibangun, apakah sistem tersebut sesuai dengn kebutuhan ataupun dengan tujuan yang akan dicapai oleh instansi terkait. Analisis kebutuhan sistem terdiri dari analisis kebutuhan perangkat keras (hardware), kebutuhan perangkat lunak (software) dan kebutuhan pengguna (brainware). Adanya aplikasi ini diharapkan dapat membantu proses pengolahan dan pengarsipan data PPNPN agar lebih efektif sehingga penyajian laporannya pun bisa lebih cepat dan mudah

\section{Rancangan Model Sistem}

Rancangan model sistem adalah suatu gambaran sistem yang masih bersifat abstrak, merupakan gabungan beberapa elemen yang terpisah kedalam satu kesatuan yang utuh dan fungsionalitas. Perancangan model sistem ini dibuat berdasarkan hasil analisis sistem untuk menyelesaikan permasalahan yang ada.

\section{Contex Diagram}

Diagram konteks adalah diagram yang menggambarkan hubungan antar entitas eksternal dengan sistem yang akan dibangun. Dimana data yang dimasukkan oleh bagian komponen eksternal dan diproses di dalam sistem dan akan menghasilkan laporan yang diinginkan oleh komponen eksternal tersebut sesuai dengan data yang dimasukan.

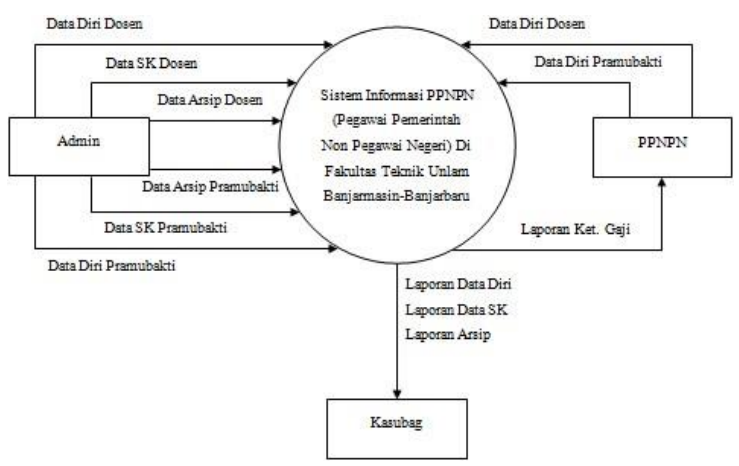

\section{DFD (Data Flow Diagram)}

DFD merupakan suatu model logika data atau proses yang dibuat untuk menggambarkan dari mana asal data dan kemana tujuan data yang keluar dari sistem.

\section{DFD Level 0}

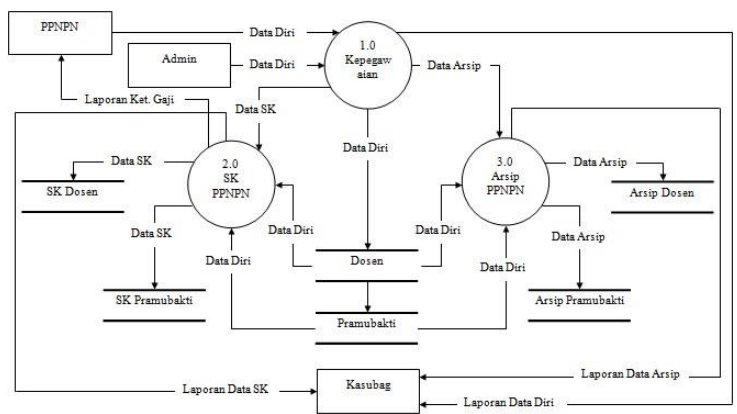

\section{DFD Level 1 proses 1}

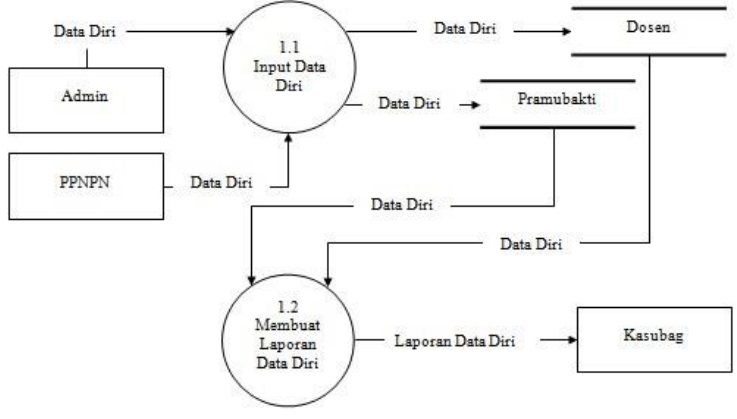

DFD Level 1 proses 2

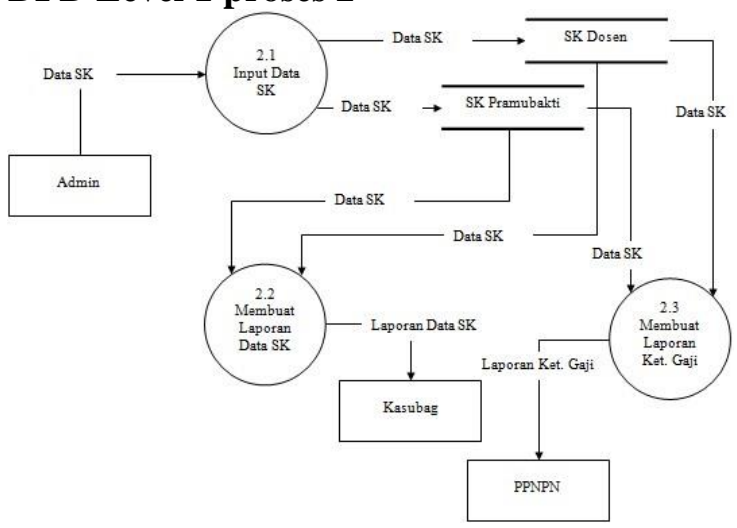

DFD Level 1 proses 3

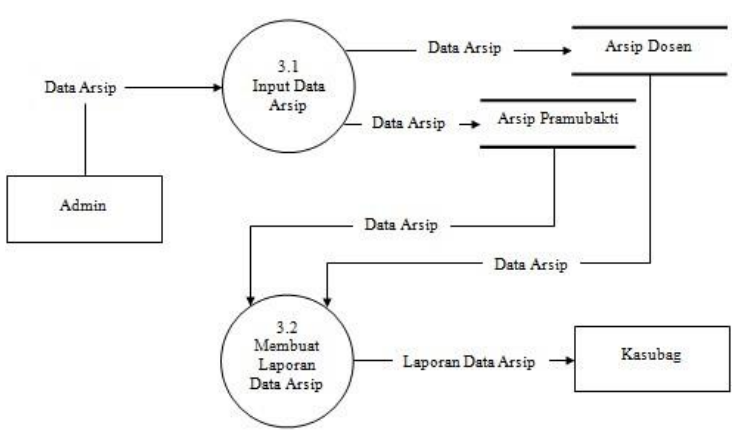




\section{Tampilan Aplikasi}

\section{Form Menu Login}

Form menu login adalah tampilan sebelum memasuki form login. Berikut tampilan form menu login:

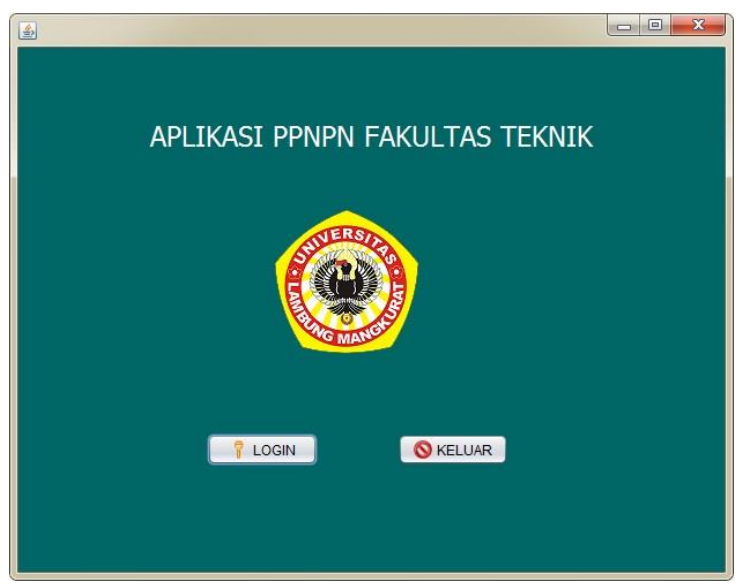

2. Form Login

Form login adalah pintu masuk ke dalam sistem yang berfungsi untuk menjaga keamanan data agar tidak semua orang dapat masuk dan mengakses kecuali orang-orang yang telah terdaftar. Berikut tampilan form login:

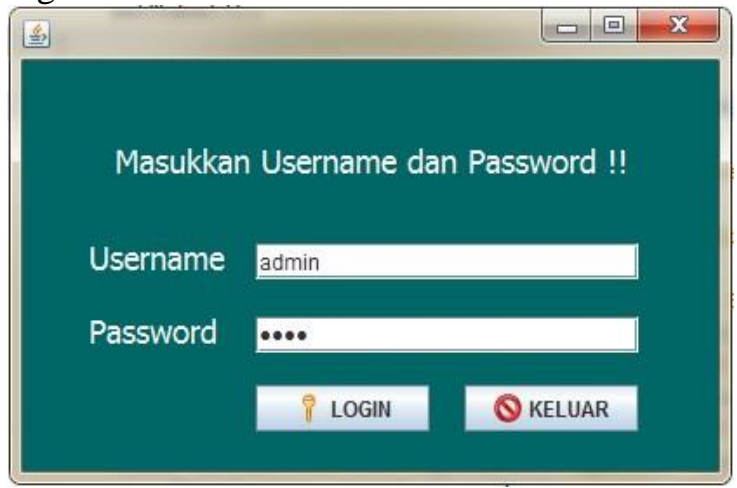

\section{Form Menu Utama}

Form menu utama adalah tampilan keseluruhan untuk menghubungkan ke menumenu lainnya. Berikut tampilan form menu utama:

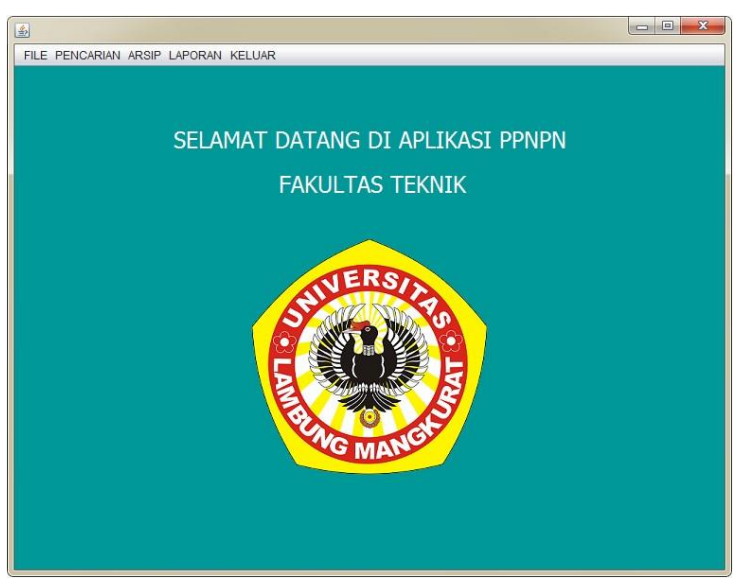

4. Form Data Diri Dosen

Form data diri dosen adalah form input data diri dosen dan berfungsi juga untuk menampilkan data diri dosen. Berikut tampilan form data diri dosen:

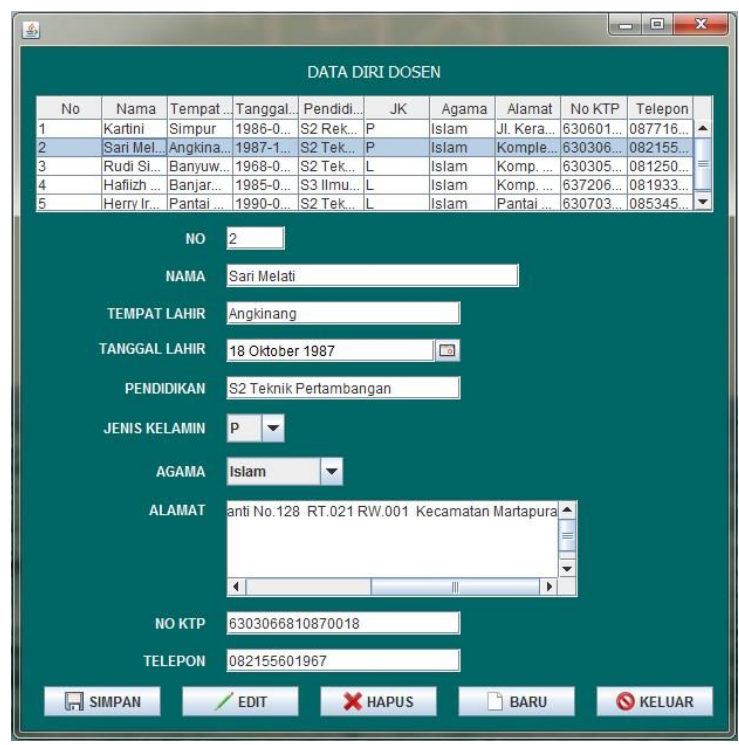

\section{Form Data Diri Pramubakti}

Form data diri pramubakti adalah form input data diri pramubakti dan berfungsi juga untuk menampilkan data diri pramubakti. Berikut tampilan form data diri pramubakti: 


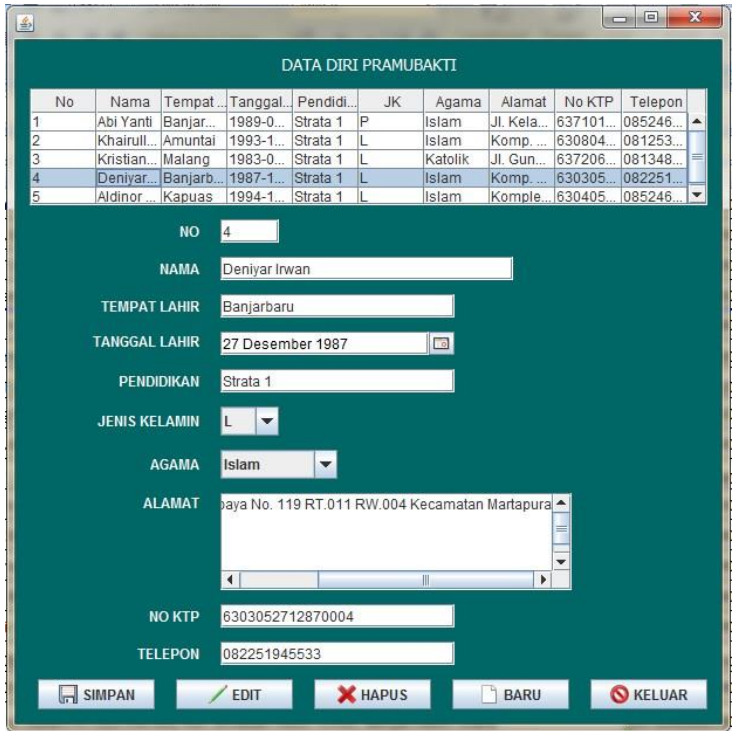

6. Form Pencarian Data Diri Dosen

Form pencarian data diri dosen adalah form pencarian data diri dosen dan berfungsi juga untuk menampilkan data diri dosen. Berikut tampilan form pencarian data diri dosen:

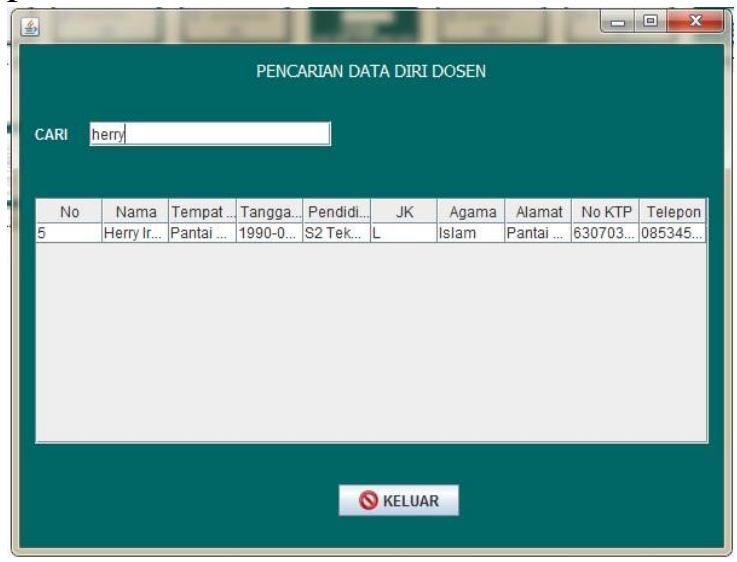

\section{Form Input Data Arsip Dosen}

Form data arsip dosen adalah form input data arsip dosen. Berikut tampilan form data arsip dosen:

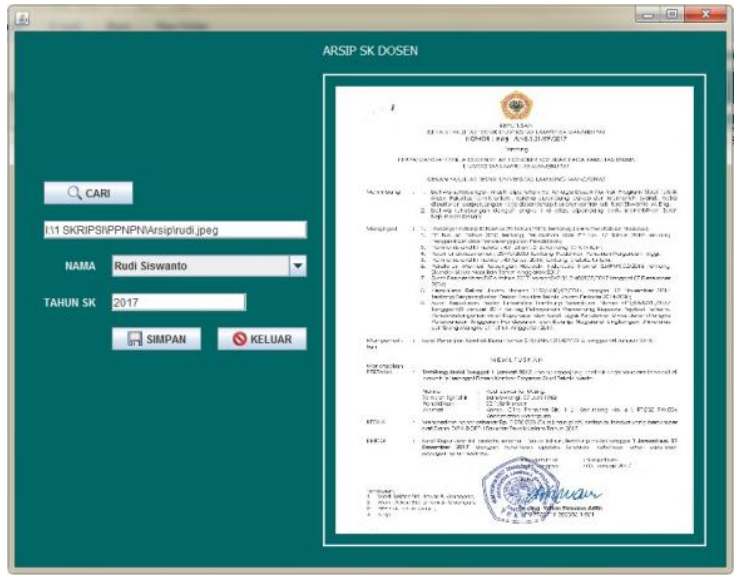

\section{Laporan Data Diri Dosen}

Laporan data diri dosen menampilkan informasi data diri dosen yang sudah diinput ke dalam sistem yang nantinya akan dicetak. Berikut tampilan laporan data diri dosen:

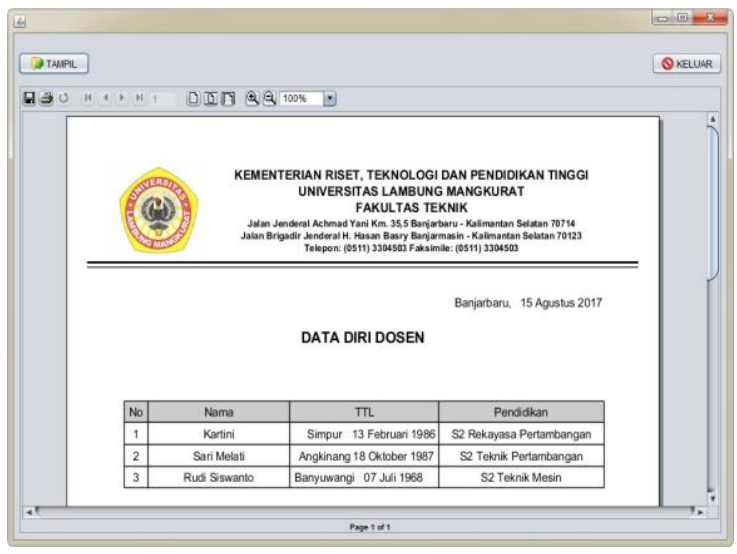

9. Laporan Data Diri Pramubakti

Laporan data diri pramubakti menampilkan informasi data diri pramubakti yang sudah diinput ke dalam sistem yang nantinya akan dicetak. Berikut tampilan laporan data diri pramubakti:

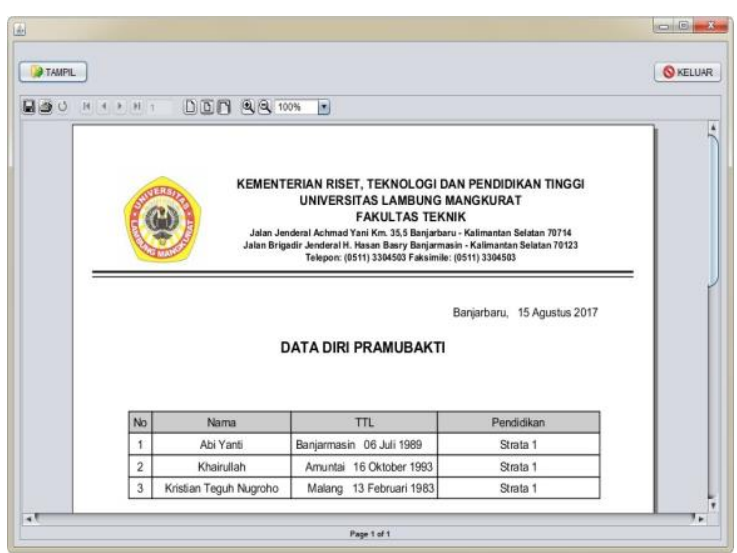




\section{Keterangan Gaji Dosen}

Laporan keterangan gaji dosen menampilkan informasi data SK dosen yang sudah diinput ke dalam sistem yang nantinya akan dicetak. Berikut tampilan laporan keterangan gaji dosen:

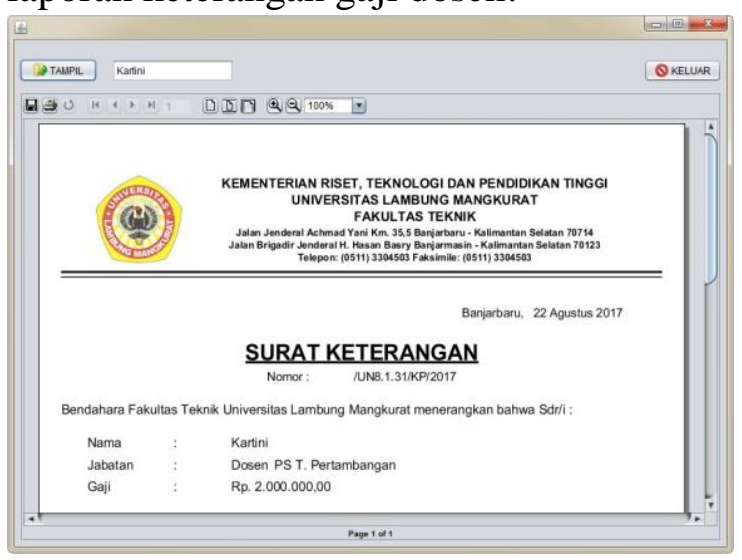

\section{Data Arsip Dosen}

Laporan data arsip dosen menampilkan informasi data arsip dosen yang sudah diinput ke dalam sistem yang nantinya akan dicetak. Berikut tampilan laporan data arsip dosen:

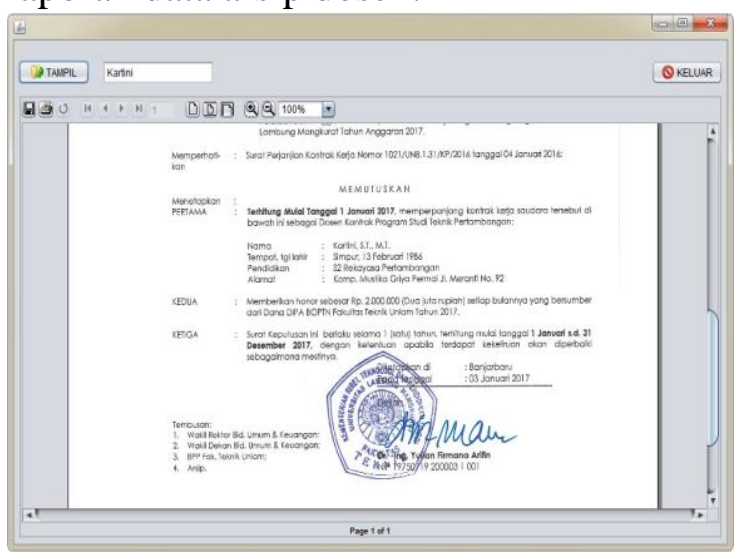

\section{KESIMPULAN}

Dapat disimpulkan penelitian ini menghasilkan aplikasi sebagai berikut:

1. Aplikasi ini mempermudah admin dalam melakukan pengolahan dan pengarsipan data PPNPN.

2. Aplikasi ini mempercepat proses dalam pengolahan dan pengarsipan data diri, SK dan surat keterangan gaji PPNPN.
3. Data-data dapat dengan mudah tersimpan secara terpadu dengan menggunakan aplikasi ini.

4. Dokumen dicetak dalam format yang seragam dengan menggunakan aplikasi ini.

\section{DAFTAR PUSTAKA}

Angga Permana. (2014). Sistem Informasi Tenaga Kontrak Kerja Di PT. Pos Indonesia (Persero). Bandung: Universitas Komputer Indonesia.

Arjun. (2010, Januari 18). Pengertian Arsip Dan Kearsipan Menurut UU Nomor 43 Tahun 2009. Retrieved from http://www.duniaarsip.com/: http://www.duniaarsip.com/pengertianarsip-dan-kearsipan-menurut-uu-nomor43-tahun-2009.html/

Bunafit Nugroho. (2008). Aplikasi pemrograman web dinamis dengan PHP dan MySQL. Yogyakarta: Gava Media.

Febriansyah Dafinci. (2010). Aplikasi Database Karyawan Outsource Pada PT. Limapilar Teknologi. Jakarta: Universitas Islam Negeri Syarif Hidayatullah.

Jogiyanto HM. (2005). Analisis dan Disain Informasi Pendekatan Terstruktur Teori dan Praktek Aplikasi Bisnis. Yogyakarta: Andi Offset.

Kurniawan, H., Eri, M., \& Nur, R. (2011). Aplikasi Penjualan Dengan Program Java Netbeans, Xampp, dan iReport. Jakarta: Elex Media Komputindo.

Portal KPPN. (2016, Agustus 18). Apa itu PPNPN ? Retrieved from http://portalkppn.com/: http://portalkppn.com/tutorialaplikasi/ppnpn/apa-itu-ppnpn/

Shalahuddin, M., \& Rosa, A. (2010). Pemrograman J2ME Belajar Cepat Pemrograman Perangkat Telekomunikasi Mobile. Bandung: Informatika. 
Tata Sutabri. (2012). Analisis Sistem Informasi. Yogyakarta: Andi.

Th Ari Prabawati. (2010). Pengembangan aplikasi data base berbasis javaDB dengan Netbeans. Andi: Yogyakarta.
Tri Sarwono Wibowo. (2014). Sistem Informasi Pengelolaan Data Karyawan Outsourcing Pada PT. Spektra Bandung. Bandung: Universitas Komputer Indonesia. 